\title{
Candidate Gene, SmCPR1, Encoding CPR1 Related to Plant Height of the Eggplant Dwarf Mutant $d w f$
}

\author{
Yang Lu ${ }^{1,2,+}$, Shuangxia Luo ${ }^{1, \dagger}{ }^{\dagger}, \mathrm{Na} \mathrm{Li}^{1}{ }^{1}$, Qiang Li ${ }^{1}$, Wenchao Du ${ }^{1}$, Weiwei Zhang ${ }^{3}$, Ping Yu ${ }^{1}$, Shuxin Xuan ${ }^{1}$, \\ Yanhua Wang ${ }^{1}$, Jianjun Zhao ${ }^{1}$, Xueping Chen ${ }^{1, *}$ and Shuxing Shen ${ }^{1, *}$ \\ 1 Key Laboratory for Vegetable Germplasm Enhancement and Utilization of Hebei, Collaborative Innovation \\ Center of Vegetable Industry in Hebei, College of Horticulture, Hebei Agricultural University, \\ Baoding 071000, China; luyangmm@cdmc.edu.cn (Y.L.); yylsx@hebau.edu.cn (S.L.); \\ yyln@hebau.edu.cn (N.L.); lqsdau@163.com (Q.L.); dwchge@163.com (W.D.); yp18233221787@163.com (P.Y.); \\ yyxsx@hebau.edu.cn (S.X.); yywyh@hebau.edu.cn (Y.W.); jjz1971@aliyun.com (J.Z.) \\ 2 Hebei University R\&D Center for Sericulture and Specialty Enabling Technologies, Institute of Sericulture, \\ Chengde Medical University, Chengde 067000, China \\ 3 College of Life Sciences, Hebei Agricultural University, Baoding 071000, China; shmzww@hebau.edu.cn \\ * Correspondence: chenxueping@hebau.edu.cn (X.C.); shensx@hebau.edu.cn (S.S.) \\ + These authors contributed equally to this work.
}

check for updates

Citation: Lu, Y.; Luo, S.; Li, N.; Li, Q.; Du, W.; Zhang, W.; Yu, P.; Xuan, S.; Wang, Y.; Zhao, J.; et al. Candidate Gene, SmCPR1, Encoding CPR1 Related to Plant Height of the Eggplant Dwarf Mutant dwf. Horticulturae 2021, 7, 196 https://doi.org/10.3390/ horticulturae7070196

Academic Editor: Liwang Liu

Received: 17 May 2021

Accepted: 12 July 2021

Published: 16 July 2021

Publisher's Note: MDPI stays neutral with regard to jurisdictional claims in published maps and institutional affiliations.

Copyright: (c) 2021 by the authors. Licensee MDPI, Basel, Switzerland. This article is an open access article distributed under the terms and conditions of the Creative Commons Attribution (CC BY) license (https:// creativecommons.org/licenses/by/ $4.0 /)$.
Abstract: Eggplant is a vegetable crop with high economic value that is cultivated worldwide. The dwarf mutant is an important germplasm material that has been extensively used in crop breeding. However, no eggplant dwarf mutants have been reported, and little is known regarding the genes responsible for dwarfism in eggplant. In this study, we isolated an eggplant dwarf mutant (dwf) from an ethyl methyl sulfonate (EMS)-induced mutant library. Genetic analysis revealed that $d w f$ was caused by a single recessive gene. A candidate gene $S m C P R 1$, encoding cytochrome P450 reductases (CPR1), was identified by bulked segregant analysis (BSA). Mutation from G to A at 8216 bp of SmCPR1 resulted in mutation of the amino acid from valine to isoleucine. The results of KASP and Sanger sequencing further support the conclusion that $S m C P R 1$ is a candidate gene responsible for the dwarfism of $d w f$. Moreover, the activity of SmCPR1 was significantly increased in $d w f$, which might be a response to dwarfism in $d w f$.

Keywords: eggplant; dwarf mutant; BSA; SmCPR1

\section{Introduction}

Eggplant (Solanum melongena L.) is a vegetable crop that is cultivated worldwide, and China is the largest eggplant producer in the world (http:/ / www.fao.org/faostat/ en/, 10 December 2020). Plant height of eggplant affects the planting density and fruit coloring especially under protected cultivation. Larger plants increase the cost of labor as well as water and fertilizer inputs in production management. Dwarfism is a desirable trait in eggplant breeding that confers higher lodging resistance and allows simplified management and harvest [1-3].

Dwarf mutants have been used as important germplasms in crop breeding since the Green Revolution. The cultivation of dwarf cultivars has been successfully applied in wheat $[4,5]$, maize [6,7], rice [8,9], and other crops [10,11]. However, the use of dwarf germplasms for eggplant breeding has largely been lagging. Therefore, there is a great need to create or discover dwarf materials in eggplant.

Here, we isolated a dwarf mutant, $d w f$, from an ethyl methyl sulfonate (EMS) mutant library in inbred lines '14-345'. Genetic analysis showed that the dwarfism of $d w f$ was controlled by a signal recessive gene. We discovered by Mutmap and KASP that the mutation responsible for the dwarfism might be a non-synonymous base pair change in SmCPR1. As compared with wild type, $d w f$ had significantly increased NADPH-cytochrome P450 reductase (CPR1) activity. 


\section{Materials and Methods}

\subsection{Plant Materials and Growth Conditions}

The dwarf mutant $d w f$ was isolated from a mutant library generated by ethyl methane sulfonate (EMS) mutagenesis from the inbred line '14-345'. The plants were grown in the greenhouse of Hebei Agricultural University.

\subsection{Genetic Analysis}

The dwf mutant was crossed with ' $14-345^{\prime}$ reciprocally. $\mathrm{F}_{1}$ plants were self-pollinated to generate $F_{2}$ populations for genetic analysis. The numbers of dwarf plants and plants with normal plant height were counted separately. The chi-square test was used for genetic analysis with SPSS.

\subsection{Candidate Gene Identification Using BSA-Seq}

The bulked segregation analysis (BSA) strategy was employed for quick identification of molecular markers linked with the dwarf phenotype. Young leaves of WT and $d w f$ were sampled for DNA extraction using the CTAB-based method. Equal amounts of DNA from 30 dwarf and 30 wild-type plants were bulked to generate the dwarf bulk (aa) and normal bulk (AA or Aa). Paired-end sequencing was performed on an Illumina HiSeqTM PE150. High-quality clean reads were obtained from raw reads by removing the data (1) with $\geq 10 \%$ unidentified nucleotides (N), (2) with $>50 \%$ bases having Phred quality $<5$, (3) with $>10$ nt aligned to the adapter, allowing $\leq 10 \%$ mismatches, and (4) putative PCR duplicates generated by PCR amplification during library construction. Then, the clean data were aligned to the reference genome (https:/ / www.ncbi.nlm.nih.gov / genome/?term=Solanum+melongena, 28 August 2018) by (Burrows-Wheeler Aligner (BWA) [12]. The alignment files were converted to BAM files using SAMtools, GATK3.8, and ANNOVAR [13-15] and were used for SNP/InDel detection and annotation. We used the wild type as the reference and to determine the read number for the parent's genotype or the dwarf genotype in the offspring pool. Then, the ratio of the number of different reads to the total number was calculated, which is the SNP/InDel index of the base sites. The average of all SNP/InDel indices in each window was used as the SNP/InDel index for this window. Usually, we applied a window size of $1 \mathrm{Mb}$ and a step size of $1 \mathrm{~kb}$ as default settings to reflect the distribution of the SNP index. The difference in the SNP/InDel index of the two pools was calculated as the $\triangle(\mathrm{SNP} / \mathrm{InDel}$ index $)$. At the $95 \%$ confidence level, $\triangle(\mathrm{SNP} / \mathrm{InDel}$ index $)>0.5$ was used as the condition, and the genes that caused stop/loss, stop/gain, nonsynonymous mutation, or variable splicing were selected as candidate genes. The library preparation and sequencing were conducted by the Novogene Technology Company in Beijing, China.

\subsection{Verification of the Candidate SNP Genotype}

Sixty-four $\mathrm{M}_{3}$ plants, $118 \mathrm{~F}_{2}$ plants, $10 \mathrm{~F}_{1}$ plants, three $d w f$, and three WT were used in the genotypic assay by Kompetitive Allele-Specific PCR (KASP). Specific primers flanking the candidate SNPs were designed and used for confirmation of the candidate SNPs by Sanger sequencing. A fragment of $601 \mathrm{bp}$ including the candidate SNP in the middle was used to perform PCR amplification (forward primer $5^{\prime} \rightarrow 3^{\prime}$ AGAGAGATAAAGGATCAATGGAGTC; reverse primer $5^{\prime} \rightarrow 3^{\prime}$ CTCTCCACTGTCTCACCTACTACC). The PCR product was purified using a kit (Sangon B518141) and sequenced at 3730XL (Life Technologies, South San Francisco, CA, USA). The data were analyzed using sequence analysis software and mapped using SeqMan software 12.2.

\subsection{Validation of Selected Genes Using Real-Time Quantitative Reverse Transcription PCR (qRT-PCR)}

RNA from the leaves and stems of 4-leaf seedlings was analyzed by quantitative real-time RT-PCR. First-strand cDNA was synthesized using RevertAid Premium Reverse Transcriptase (Thermo Scientific ${ }^{\mathrm{TM}}$ EP0733, Waltham, MA, USA) according to the manufac- 
turer's instructions. GAPDH (GenBank JX448342.1) was used as the internal control [16], and primer sequences for the genes analyzed are listed in Table 1. qRT-PCRs were run in a Lightcycler 96 Real-time qPCR detection system (Roche, Indianapolis, IN, USA) with three biological replicates for each type of sample. The program used was as follows: $5 \mathrm{~min}$ at 95 ${ }^{\circ} \mathrm{C}, 40$ cycles of $95^{\circ} \mathrm{C}(10 \mathrm{~s}), 58^{\circ} \mathrm{C}(10 \mathrm{~s})$, and $72{ }^{\circ} \mathrm{C}(30 \mathrm{~s})$. The $2^{-\triangle \Delta \mathrm{Ct}}$ method was used to calculate the relative expression levels of the target genes [17].

Table 1. The primer sequences for qRT-PCR.

\begin{tabular}{ccc}
\hline Gene ID & Forward Primer Sequence $\mathbf{( 5}^{\prime} \mathbf{- 3}^{\prime} \mathbf{)}$ & Reverse Primer Sequence $\mathbf{( 5}^{\prime} \mathbf{- 3}^{\prime} \mathbf{)}$ \\
\hline GAPDH & GTACGACAACGAATGGGGTTA & TCATATCAGCAGCACCAGCA \\
\hline$S m C P R 1$ & CGAGTGGCCCAATCAACAGAT & CCGTCCTCCTCCTCCTCCAAAACCG \\
\hline$C P R 2$ & GAAAGAACCACTATGCGTATAAACATC & CACCGTGTTTGTTTGTTTGTG \\
\hline
\end{tabular}

\subsection{NADPH-Cytochrome P450 Reductase Activity Assay}

The activity of NADPH-cytochrome P450 reductase (CPR) in stems was assayed using a Plant CPR ELISA kit (Yuanmu, Shanghai). The Stop Solution changes the color from blue to yellow, and the intensity of the color is measured at $450 \mathrm{~nm}$ using a spectrophotometer. To measure the concentration of CPR in the sample, the CPR ELISA Kit includes a set of calibration standards. The calibration standards were assayed at the same time as the samples and allowed the operator to produce a standard curve of optical density versus CPR concentration. Then, the concentration of CPR in the samples was determined by comparing the O.D. of the samples to the standard curve.

\subsection{Statistical Analysis}

Statistical analyses were performed using Student's $t$-test (SPSS 21.0) [18]. Summary statistics are presented as the mean \pm standard deviation (SD). Asterisks denote significant differences $\left({ }^{*} p<0.05\right.$ and $\left.{ }^{* *} p<0.01\right)$.

\section{Results}

\subsection{Inheritance of the Dwarf Phenotype in dwf}

The dwf mutant, which showed a significantly dwarfed phenotype due to shortened internodes, was isolated from $\mathrm{M}_{2}$ populations derived from an EMS-mutagenized eggplant '14-345' (WT) population [19]. To determine the inheritance pattern of dwarfism in dwfs, $\mathrm{F}_{1}$ plants that displayed similar plant heights to WT were obtained from crosses of $d w f s$ with WT (Figure 1). The dwarf phenotype was segregated in the $\mathrm{F}_{2}$ populations. There were 43 plants with a dwarf phenotype and 123 plants with plant height similar or close to that of WT in the $F_{2}$ population, which fit a 3:1 segregation ratio by the chi-square test $\left(\chi^{2}<\chi_{0.05}^{2}=3.84\right)$ (Table 2). These results suggested that the dwarf phenotype of $d w f$ was controlled by a single nuclear recessive gene.

Table 2. The segregation ratio of $\mathrm{F}_{2}$.

\begin{tabular}{ccccc}
\hline Generation & WT Phenotype & $\begin{array}{c}\text { Dwarf } \\
\text { Phenotype }\end{array}$ & $\begin{array}{c}\text { Theoretical } \\
\text { Segregation Ratio }\end{array}$ & $\chi^{2}$ \\
\hline $\mathrm{F}_{2}$ & 123 & 43 & $2.86: 1$ & 0.823 \\
\hline
\end{tabular}



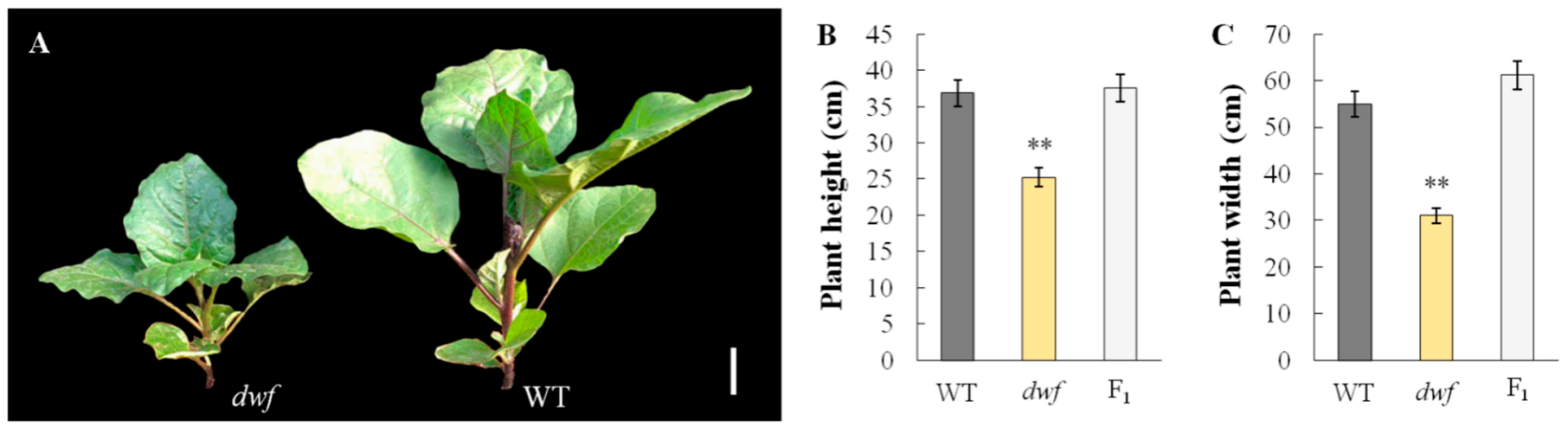

Figure 1. Comparisons of plant height and width of $d w f, \mathrm{WT}$, and $\mathrm{F}_{1}$ plants. ${ }^{* *}$ Significantly different at $p=0.01$ by the $t$ test. (A) The plants of $d w f$ and WT; (B) The plant height of the $d w f$, WT and $\mathrm{F}_{1}$; (C)The plant width of the $d w f, \mathrm{WT}$ and $\mathrm{F}_{1}$.

\subsection{Identification of a Candidate Gene by BSA}

BSA-seq was used to identify the candidate gene for $d w f$. Two bulk DNA samples, dwarf bulk (M-bulk) and normal bulk (W-bulk), were constructed by mixing equal amounts of DNAs from 30 dwarf plants and 30 normal plants from the $\mathrm{M}_{3}$ population, respectively. We obtained clean reads of $26.56 \mathrm{~Gb}$ (99.87\% coverage) and $26.20 \mathrm{~Gb}(99.89 \%$ coverage) corresponding to the W-bulk and M-bulk, respectively; $97.71 \%$ and $96.74 \%$ of the reads from W-bulk and M-bulk were aligned to the reference genome (https:/ /www.ncbi.nlm. nih.gov / genome/?term=Solanum+melongena, 28 August 2018). A total of 3077032 SNPs were identified between the M-bulk and W-bulk. $\triangle$ (SNP-index) $>0.5$ was used as the threshold at the 95\% confidence level, 13 SNPs including six nonsynonymous SNPs, a stop gain SNP, a splicing SNP, and seven upstream SNPs were obtained (Table 3).

Table 3. Candidate SNP sites.

\begin{tabular}{cccccc}
\hline Gene ID & Variant & Scaffold & Position & Reference & Alter \\
\hline Sme2.5_01158.1_g00001.1 & Nonsynonymous & Sme2.5_01158.1 & 8216 & $\mathrm{G}$ & $\mathrm{A}$ \\
\hline Sme2.5_00670.1_g00001.1 & Nonsynonymous & Sme2.5_00670.1 & 1811 & $\mathrm{C}$ & $\mathrm{A}$ \\
\hline Sme2.5_06691.1_g00001.1 & Nonsynonymous & Sme2.5_06691.1 & 1988 & $\mathrm{~T}$ & $\mathrm{C}$ \\
\hline Sme2.5_11667.1_g00003.1 & Nonsynonymous & Sme2.5_11667.1 & 28,891 & $\mathrm{C}$ & $\mathrm{T}$ \\
\hline Sme2.5_16807.1_g00001.1 & Nonsynonymous & Sme2.5_16807.1 & 1476 & $\mathrm{C}$ & $\mathrm{T}$ \\
\hline Sme2.5_19952.1_g00001.1 & Nonsynonymous & Sme2.5_19952.1 & 2943 & $\mathrm{G}$ & $\mathrm{T}$ \\
\hline Sme2.5_21615.1_g00001.1 & Stop gain & Sme2.5_21615.1 & 2478 & $\mathrm{C}$ & $\mathrm{T}$ \\
\hline Sme2.5_08332.1_g00001.1 & Splicing & Sme2.5_08332.1 & 3974 & $\mathrm{C}$ & $\mathrm{T}$ \\
\hline Sme2.5_01689.1_g00001.1 & Upstream & Sme2.5_01689.1 & 4262 & $\mathrm{~A}$ & $\mathrm{~T}$ \\
\hline Sme2.5_01689.1_g00001.1 & Upstream & Sme2.5_01689.1 & 4265 & $\mathrm{C}$ & $\mathrm{G}$ \\
\hline Sme2.5_06855.1_g00002.1 & Upstream & Sme2.5_06855.1 & 10,623 & $\mathrm{C}$ & $\mathrm{T}$ \\
\hline Sme2.5_19942.1_g00002.1 & Upstream & Sme2.5_19942.1 & 11,896 & $\mathrm{~T}$ & $\mathrm{C}$ \\
\hline Sme2.5_22728.1_g00001.1 & Upstream & Sme2.5_22728.1 & 4016 & $\mathrm{G}$ & $\mathrm{A}$ \\
\hline
\end{tabular}

To further confirm the candidate SNP responsible for the dwarf phenotype, the 13 SNPs were used in KASP to design a specific primer for genotyping analysis of the $64 \mathrm{M}_{3}$ plants, $118 \mathrm{~F}_{2}$ plants, $10 \mathrm{~F}_{1}$ plants, three $d w f$, and three WT. The genotypic assay revealed that SNP 8216 of Sme2.5_01158.1 cosegregated with the phenotype in the $\mathrm{M}_{3}$, $\mathrm{F}_{2}, \mathrm{~F}_{1}$ populations and parents. The dwarf plants had a A:A genotype, and the plants with a wild phenotype had a G:G or G:A genotype (Figure 2). Then, the candidate SNP Sme2.5_01158.1_g00001.1 was used to design a specific primer for genotyping analysis from 
ten $\mathrm{F}_{2}$ individuals by Sanger sequencing. The results showed that the SNP genotype of the dwarf phenotype was A:A, and the genotype of WT was G:A and G:G (Figure 3). Therefore, we confirmed that Sme2.5_01158.1_g00001.1 was a candidate gene related to dwarfism.
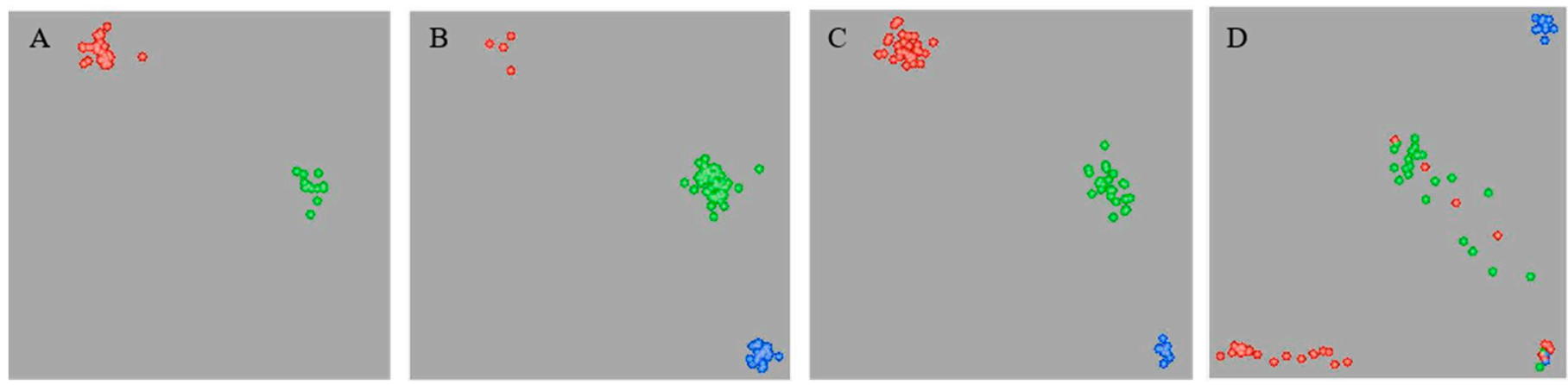

Figure 2. Verification of Sme2.5_01158.1_g00001.1 by KASP, the four charts represent four plates respectively. Red points indicate genotype A:A, green points indicate A:G, and blue points indicate $G: G:(A) 10 F_{1}$ plants with the genotype A:G, 20 dwarf plants with genotype $\mathrm{A}: \mathrm{A}$ of the $\mathrm{F}_{2}$ population; (B) 4 dwarf plants with the genotype $\mathrm{A}: \mathrm{A}$ of the $\mathrm{F}_{2}$ population and 90 wild plants with the genotype A:G and G:G of the $\mathrm{F}_{2}$ population; (C) 3 WT plants, 3 dwf plants, 14 dwarf plants with the genotype A:A of the $\mathrm{M}_{3}$ population; (D) 16 dwarf plants with the genotype A:A of the $\mathrm{M}_{3}$ population, 21 wild plants with A:G and 13 with $G: G$ of the $M_{3}$ population, and $4 \mathrm{~A}: G$ of the $F_{2}$ population.

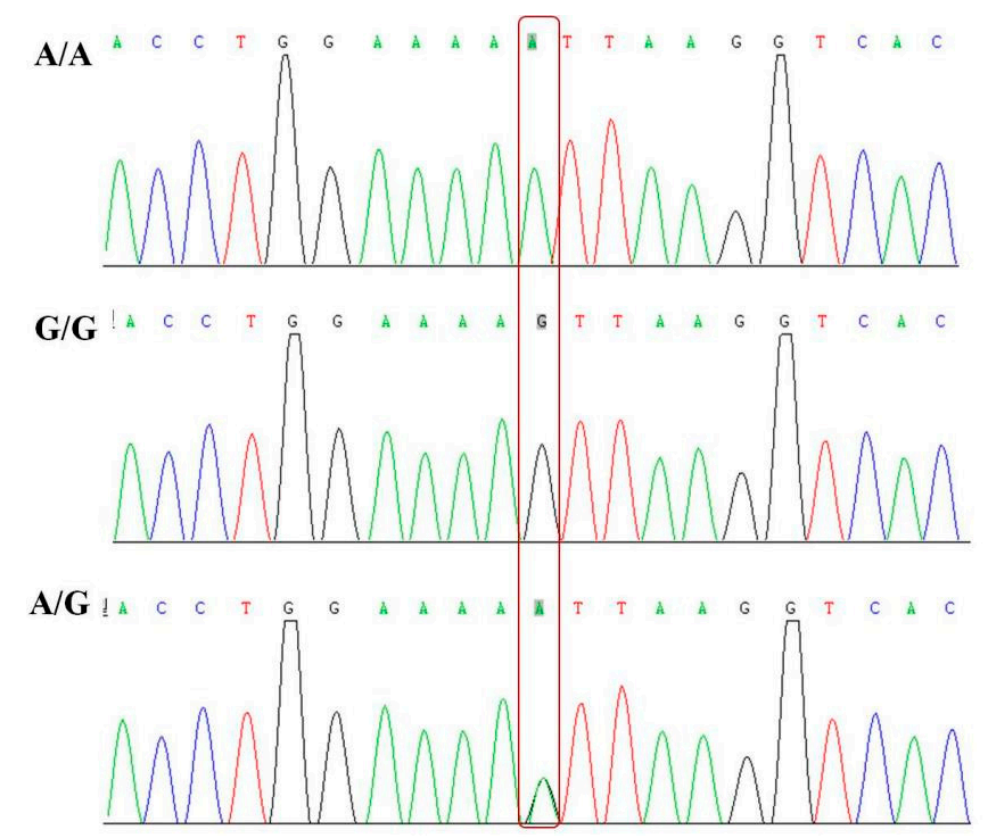

Figure 3. Sanger sequencing revealed the genotype of the Sme2.5_01158.1_g00001.1 mutation site. The top figure shows the dwarf phenotype in which the genotype was A:A. The middle and bottom figures show the wild-type phenotype, and the genotypes were G:G and A:G.

Sme2.5_01158.1_g00001.1, locating at 12663065-12667066 on chromosome 4 (Figure 4A), contains open reading frame of $3912 \mathrm{bp}$ and encoding NADPH-cytochrome P450 reductase 1 (CPR1) of 1154 amino acids. Thus, we named Sme2.5_01158.1_g00001.1 as SmCPR1. In order to understand the effect of base mutation on protein, we used ORF finder (http:/ / www.ncbi.nlm.nih.gov/orffinder/, 15 January 2020) to predict domain and MAFFT software to do the amino acid sequence homology alignment. We found the mutation that carried a G to A transition at nucleotide 8216 (Figure 4B) led to a transition at codon 77, resulting in replacement of a valine (Val) with isoleucine (Ile), and the substitution in the fourth site in front of the flavodoxin domain (Figure $4 \mathrm{C}$ ). These results suggest that the 
mutation in SmCPR1 may cause the dwarf phenotype of mutant dwf. Additionally, we found that the amino acid mutation was located in 4 amino acids upstream of flavodoxin domain, which is a conserved domain of NADPH-cytochrome P450 reductase.

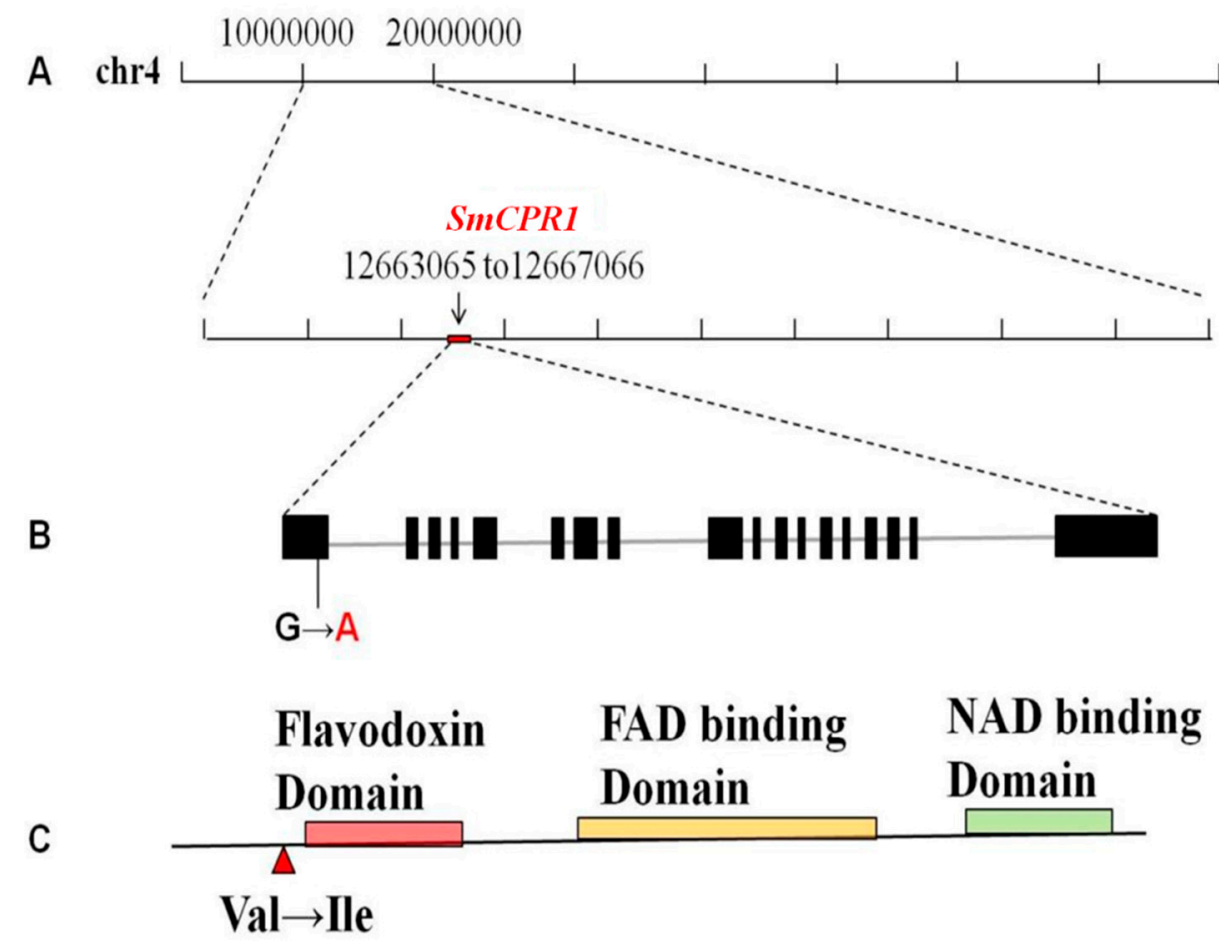

Figure 4. Location and structure of the candidate gene $S m C P R 1$ and its amino acid sequence: (A) SmCPR1 is located on chromosome 4, and the red frame indicates SmCPR1; (B) structure and mutation site of SmCPR1, black rectangles indicate exons and gray lines indicate introns, the mutation occurred in the first exon and the mutation base was from $G$ to $A ;(C)$ the black line indicates the amino sequence, and the red, yellow, and green rectangles indicate the conserved domain database. FAD, flavin adenine dinucleotide. NAD, nicotinamide adenine dinucleotide.

\subsection{Effect of SmCRP Mutation on Enzyme Activity}

CPRs play a vital role in CYP metabolism in plants. Two CPR genes, SmCPR1 and $S m C P R 2$, were identified in eggplant genome. In order to confirm the physiological function of SmCPR1, the relative transcription level of SmCPR1 and NADPH-cytochrome P450 reductase (CPR) activity were studied in stems of WT and dwf. As shown in Figure 5A, SmCPR2 showed very low expression in both leaves and stems. Although SmCPR1 was barely expressed in leaves, the expression of SmCPR1 was highly expressed in stems. The results indicated the important role of $S m C P R 1$ in regulating the development of stem, which is the main factor determining plant height. The CPR activity was analyzed using CPR ELISA kit. CPR activity was significantly increased in the stems of $d w f$ as compared with that of WT (Figure 5B), indicating the negative roles of SmCPR1 in regulating plant height in eggplant. 

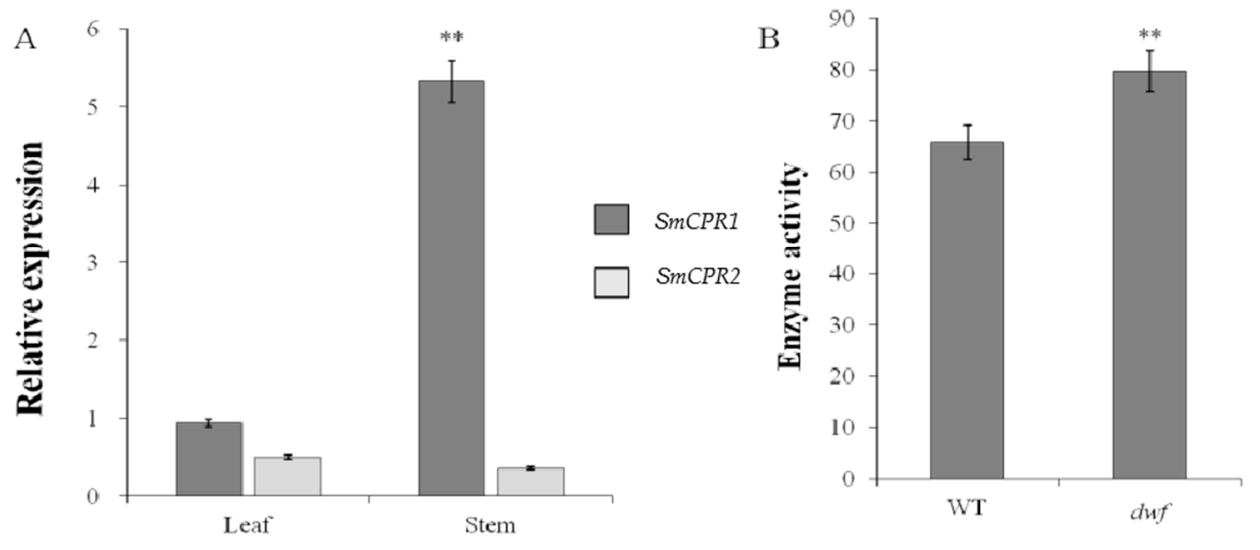

Figure 5. Relative expression and enzyme activity: (A) Expression pattern of SmCPR1 and SmCPR2 in leaves and stems; (B) CPR enzyme activity assayed in the stems of WT and $d w f$.

\section{Discussion}

Plant height is an important agronomic trait for crops and is highly associated with agricultural performance. Dwarfism or semi-dwarfism is widely used in plant breeding and is easier to manage and harvest, with considerable cost savings [20,21]. EMS mutagenesis is one of the effective methods to establish a mutant library; the advantages are inducing point mutation and easy to be stably inherited [22-24]. In this study, we established a mutant library by EMS with various phenotypes and isolated a dwarf mutant $d w f$ from the mutant library. The $\mathrm{F}_{1}$ plants which were obtained from the crosses of $d w f$ with WT displayed similar plant height with WT, and the $\mathrm{F}_{2}$ populations showed segregated phenotype and the ratio of wild type and dwarf type fit for 3:1, verifying that the dwarf phenotype was controlled by a single nuclear recessive gene.

BSA is a rapid method used to detect molecular markers associated with target traits in mapping populations [25]. In our study, we isolated the SmCPR1 gene as a candidate gene that regulate plant growth by BSA and verified this conclusion by KASP. The gene SmCPR1 carried the mutation at $8216 \mathrm{bp}$ from $\mathrm{G}$ to $\mathrm{A}$ and resulted in the 77th mutage of Val to Ile, encodes a member of NADPH- cytochrome P450 reductase (CPR), CPR1. In Arabidopsis mutant cpr1, CPR1 related to dwarfism has been reported [26].

$\mathrm{CPR}$ contains cofactors and can transfer electrons to NAD+ or NADP+ to diverse cytochrome P450 monooxygenases [27,28] which participate in substance metabolism [29] associated with dwarfism such as endogenous hormone [30,31] and phenylpropanes [32]. We have reported that the $\mathrm{GA}_{3}$ level, internode length of stems, and the internode cell length of $d w f$ were significantly decreased as compared with those of the WT, and confirmed that the dwarfism of $d w f$ was associated with gibberellin $\left(\mathrm{GA}_{3}\right)$ [19]. The SmCPR1 played a negative role in regulating the plant height in $d w f$, it might participate in the process of impeding the $\mathrm{GA}_{3}$ biosynthesis.Further study is needed to provide the direct evidence.

In this study, the expression of the mutant gene SmCPR1 was not changed, but the enzyme activity of CPR1 was significantly increased in $d w f$. We inferred that the mutant location of the amino acid was very close to the conserved domain, which might alter protein conformation and further affect enzyme activity.

Author Contributions: Conceptualization, Y.L., S.L. and X.C.; methodology, Y.L., W.D., P.Y. and S.X.; validation, Y.L., S.L. and X.C.; formal analysis, Y.L. and S.L.; investigation, W.Z.; resources, X.C., J.Z., S.L. and Y.W.; data curation, Y.L. and X.C.; writing-original draft preparation, Y.L. and S.L.; writing-review and editing, Y.L., S.L., N.L., Q.L., J.Z and X.C.; visualization, Y.L.; supervision, X.C. and S.S.; project administration, X.C. and S.S.; funding acquisition, X.C. and S.S. All authors have read and agreed to the published version of the manuscript.

Funding: This work was supported by the Hebei Fruit Vegetables Seed Industry Science and Technology Innovation Team Project; the Key R \& D Project of Hebei Province (Grant No. 20326344D); 
the Vegetable innovation team project of Hebei modern agricultural industrial technology system (Grant No. HBCT2018030203); the Vegetable Molecular Chromosome Engineering and New Variety Breeding Innovation Team of Hebei Agriculture University; and Technology Innovation Guidance Project-Science; and Technology Work Conference of Hebei Provincial Department of Science and Technology.

Institutional Review Board Statement: Not applicable.

Informed Consent Statement: Not applicable.

Data Availability Statement: Data are contained in the article.

Conflicts of Interest: The authors declare no conflict of interest.

\section{References}

1. Hedden, P. The genes of the green revolution. Trends Genet. 2003, 19, 5-9. [CrossRef]

2. Peng, J.R.; Richards, D.E.; Hartley, N.M.; Murphy, G.P.; Devos, K.M.; Flintham, J.E.; Beales, J.; Fish, L.J.; Worland, A.J.; Pelica, F. 'Green revolution' genes encode mutant gibberellin response modulators. Nature 1999, 400, 256-261. [CrossRef] [PubMed]

3. Sasaki, A.; Ashikari, M.; Ueguchi-Tanaka, M.; Itoh, H.; Nishimura, A.; Swapan, D.; Ishiyama, K.; Saito, T.; Kobayashi, M.; Khush, G.S.; et al. A mutant gibberellin-synthesis gene in rice. Nature 2002, 416, 701-702. [CrossRef] [PubMed]

4. Jin, X.J.; Sun, D.F.; Li, H.Y.; Sun, G.L. Characterization and molecular mapping of a dwarf mutant in wheat. Genet. Mol. Res. 2013, 12, 3555-3565. [CrossRef] [PubMed]

5. Xu, T.; Bian, N.F.; Wen, M.M.; Xiao, J.; Yuan, C.X.; Cao, A.Z.; Zhang, S.Z.; Wang, X.E.; Wang, H.Y. Characterization of a common wheat (Triticum asetivum L.) high—tillering dwarf mutant. Theor. Appl. Genet. 2017, 130, 483-494. [CrossRef]

6. $\quad$ Li, C.; Tang, J.; Hu, Z.Y.; Wang, J.W.; Yu, T.; Yi, H.Y.; Cao, M.Y. A novel maize dwarf mutant generated by Ty1-copia LTRretrotransposon insertion in Brachytic2 after spaceflight. Plant Cell Rep. 2020, 39, 393-408. [CrossRef]

7. Chen, Q.; Song, J.; Du, W.P.; Xu, L.Y.; Jiang, Y.; Zhang, J.; Xiang, X.L.; Yu, G.R. Identification and genetic mapping for rht-DM, a dominant dwarfing gene in mutant semi-dwarf maize using QTL-seq approach. Genes Genom. 2018, 40, 1091-1099. [CrossRef]

8. Bae, K.-D.; Um, T.-Y.; Yang, W.-T.; Park, T.-H.; Hong, S.-Y.; Kim, K.-M.; Chung, Y.-S.; Yun, D.-J.; Kim, D.-H. Characterization of dwarf and narrow leaf (dnl-4) mutant in rice. Plant Signal Behav. 2021, 16, 1849490. [CrossRef]

9. Wei, X.J.; Tang, S.Q.; Shao, G.N.; Chen, M.L.; Hu, Y.C.; Hu, P.S. Fine mapping and characterization of a novel dwarf and narrow-leaf mutant $d n l 1$ in rice. Genet. Mol. Res. 2013, 12, 3845-3855. [CrossRef] [PubMed]

10. Xing, M.M.; Su, H.N.; Liu, X.; Yang, L.M.; Zhang, Y.Y.; Wang, Y.; Fang, Z.Y.; Lv, H.H. Morphological, transcriptomics and phytohormone analysis shed light on the development of a novel dwarf mutant of cabbage (Brassica oleracea). Plant Sci. 2020, 290, 110283. [CrossRef]

11. Hou, S.S.; Niu, H.H.; Tao, Q.Y.; Wang, S.S.; Gong, Z.H.; Li, S.; Weng, Y.Q.; Li, Z. A mutant in the CsDET2 gene leads to a systemic brassinosteriod deficiency and super compact phenotype in cucumber (Cucumis sativus L.). Theor. Appl. Genet. 2017, 130, 1693-1703. [CrossRef] [PubMed]

12. Li, H.; Durbin, R. Fast and accurate short read alignment with Burrows-Wheeler transform. Bioinformatics 2009, 25, 1754-1760. [CrossRef]

13. Li, H.; Handsaker, B.; Wysoker, A.; Fennell, T.; Ruan, J.; Homer, N.; Marth, G.; Abecasis, G.; Durbin, R. The sequence alignment/map format and SAMtools. Bioinformatics 2009, 5, 2078-2079. [CrossRef]

14. McKenna, A.; Hanna, M.; Banks, E.; Sivachenko, A.; Cibulskis, K.; Kernytsky, A.; Garimella, K.; Altshuler, D.; Gabriel, S.; Daly, M.; et al. The Genome Analysis Toolkit: A MapReduce framework for analyzing next-generation DNA sequencing data. Genome Res. 2010, 20, 1297-1303. [CrossRef]

15. Wang, K.; Li, M.; Hakonarson, H. ANNOVAR: Functional annotation of genetic variants from high-throug hput sequencing data. Nucleic Acids Res. 2010, 38, e164. [CrossRef] [PubMed]

16. Barbierato, V.; Sala, T.; Rinaldi, P.; Bassolino, L.; Barchi, L.; Rotino, G.L.; Toppino, L. A spiking strategy facilitates housekeeping selection for RT-qPCR analysis under different biotic stresses in eggplant. Protoplasma 2017, 254, 2215-2223. [CrossRef]

17. Livak, K.J.; Schmittgen, T.D. Analysis of relative gene expression data using real-time quantitative PCR and the $2^{-\Delta \Delta C T}$ method. Methods 2001, 25, 402-408. [CrossRef]

18. Mishra, P.; Singh, U.; Pandey, C.M.; Mishra, P.; Pandey, G. Application of student's $t$-test, analysis of variance, and covariance. Ann. Card. Anaesth. 2019, 22, 407-411. [CrossRef]

19. Lu, Y.; Luo, S.; Li, Q.; Li, N.; Du, W.; Yu, P.; Wang, X.; Zhang, W.; Xuan, S.; Zhou, X.; et al. Phenotypic Characterization and Differential Gene Expression Analysis Reveal That Dwarf Mutant dwf Dwarfifism Is Associated with Gibberellin in Eggplant. Horticulturae 2021, 7, 114. [CrossRef]

20. Jia, Q.J.; Li, C.D.; Shang, Y.; Zhu, J.H.; Hua, W.; Wang, J.M.; Yang, J.M.; Zhang, G.P. Molecular characterization and functional analysis of barley semi-dwarf mutant Riso no. 9265. BMC Genom. 2015, 16, 927-938. [CrossRef]

21. Sun, X.R.; Liu, L.; Zhi, X.N.; Bai, J.R.; Cui, Y.N.; Shu, J.S.; Li, J.M. Genetic analysis of tomato internode length via mixed major gene plus polygene inheritance model. Sci. Hortic. 2019, 246, 759-764. [CrossRef] 
22. Wu, Z.; Liu, Z.Z.; Chang, S.F.; Zhao, Y.X. An EMS mutant library for carrot and genetic analysis of some mutants. Breed Sci. 2020, 70, 540-546. [CrossRef]

23. Sun, J.; Luu, N.S.; Chen, Z.H.; Chen, B.; Cui, X.A.; Wu, J.X.; Zhang, Z.G.; Lu, T.G. Generation and Characterization of a Foxtail Millet (Setaria italica) Mutant Library. Front. Plant Sci. 2019, 10, 369. [CrossRef]

24. Kim, Y.; Schumaker, K.S.; Zhu, J.K. EMS mutagenesis of Arabidopsis. Methods Mol. Biol. 2006, 323, 101-103.

25. Michelmore, R.W.; Paran, I.; Kesseli, R.V. Identification of markers linked to disease-resistance genes by bulked segregant analysis: A rapid method to detect markers in specific genomic regions by using segregating populations. Proc. Natl. Acad. Sci. USA 1991, 88, 9828-9832. [CrossRef]

26. Stokes, T.L.; Richards, E.J. Induced in stability of two Arabidopsis constitutive pathogen-response alleles. Proc. Natl. Acad. Sci. USA 2002, 99, 7792-7796. [CrossRef]

27. Laursen, T.; Jensen, K.; Moller, B.L. Conformational changes of the NADPH-dependent cytochrome P450 reductase in the course of electron transfer to cytochromes P450. Biochim. Biophys. Acta (BBA)-Proteins Proteom. 2011, 1814, 132-138. [CrossRef]

28. Dae-Kyun Ro, D.-K.; Jürgen, E.; Douglas, C.J. Cloning, Functional Expression, and Subcellular Localization of Multiple NADPHCytochrome P450 Reductases from Hybrid Poplar. Plant Physiol. 2002, 130, 1837-1851.

29. Szalai, G.; Tajti, J.; Hamow, K.A.; Ildikó, D.; Khalil, R.; Vanková, R.; Dobrev, P.; Mishueva, S.P.; Janda, T.; Pál, M. Molecular background of cadmium tolerance in Rht dwarf wheat mutant is related to a metabolic shift from proline and polyamine to phytochelatin synthesis. Environ. Sci. Pollut. Res. Int. 2020, 27, 23664-23676. [CrossRef] [PubMed]

30. Nelissen, H.; Rymen, B.; Jikumaru, Y.; Demuynck, K.; Lijsebettens, M.V.; Kamiya, Y.; Inzé, D.; Beemster, G.T.S. A local maximum in gibberellin levels regulates maize leaf growth by spatial control of cell division. Curr. Biol. 2012, 22, 1183-1187. [CrossRef]

31. Bishop, G.J. Brassinosteroid mutants of crops. J. Plant Growth Regul. 2003, 22, 325-335. [CrossRef]

32. Muro-Villanueva, F.; Mao, X.; Chapple, C. Linking phenylpropanoid metabolism, lignin deposition, and plant growth inhibition. Curr. Opin. Biotechnol. 2019, 56, 202-208. [CrossRef] [PubMed] 